\title{
Häckfågelfaunan i en sydsvensk ädellövskog under 40 år - revirkartering av Ottenby lund 1972-2011
}

\author{
The breeding bird community over 40 years in a rich broadleaved forest at Ottenby \\ in southern Sweden
}

\author{
DANIEL BENGTSSON \& ÅKE LINDSTRÖM
}

\begin{abstract}
We present the results from 40 years of territory mapping of a 9 ha plot in Ottenby lund, a rich broadleaved oak forest on the island of Öland in the Baltic Sea in southeast Sweden. The plot was rich in both species and territories: 1509 territories $/ \mathrm{km}^{2}$ for all 51 species and 1474 territories $/ \mathrm{km}^{2}$ when only 38 passerines were considered. Chaffinch Fringilla coelebs and Willow Warbler Phylloscopus trochilus were the most abundant species, together $40 \%$ of the passerines. $54 \%$ of the passerine species were long-distance migrants, which made up $42 \%$ of the territories. There was a positive correlation in territory numbers between long-distance migrants and short-distance migrants/residents. Both the number of territories and the number of species increased during 1972-1991, but decreased during 1992-2011. Community and species

trends did not generally follow national trends. The reasons for the local fluctuations are poorly known. Only moderate habitat change occurred, caused by occasional cutting of understory and some trees, sudden oak death, and varying numbers of deer and cattle. Increasing number of pine marten Martes martes may have had effects.

Daniel Bengtsson, Naturvetenskapliga institutionen, Linnéuniversitetet, Barlastgatan 11, 39182 Kalmar och Ottenby fägelstation, Pl. 1500, 38065 Degerhamn. E-post: daniel.bengtsson@lnu.se

Åke Lindström, Ottenby fågelstation, Pl. 1500, 38065 Degerhamn och Biologiska institutionen, Biodiversitet, Lunds universitet, Ekologihuset, 22362 Lund
\end{abstract}

\section{Abstract}

Received 6 September 2012, Accepted 19 November 2012, D. Hasselquist

\section{Inledning}

Antalet fågelarter och fågelindivider på en plats varierar och förändras över tiden. För att kunna tolka pågående förändringar i fågelfaunan är det viktigt att kunna jämföra med långa tidsserier, gärna från relativt opåverkade miljöer. I Sverige finns flera platser som inventerats med noggranna och strikt standardiserade metoder under många år. Genom så kallad revirkartering, då upprepade besök görs under våren, kartläggs hur många revir av olika arter som förekommer. Den längsta obrutna revirkarteringsserien finns i Skåne, där Fågelsångsdalen inventerats årligen sedan 1953 (Enemar m.fl. 1994, Enemar \& Thorner 2003, Thorner 2004, 2007, Svensson m.fl. 2010). Andra långtidsundersökningar baserade på revirkartering är inventeringarna i fjällbjörkskog (sedan 1963, Enemar m.fl. 2004) och på fjällhed (sedan 1964, Svensson 2006) runt Ammarnäs i södra Lappland, lövskogsområdet Sörön i Närke (sedan 1965, Johannesson 2005, Simonsson 2008), samt lövskogen Dalby Söderskog i Skåne (15 inventeringssäsonger fördelat på totalt 27 år 1980-2006, Svensson 2009).

På nationell nivå i Sverige följs den svenska få- gelfaunans förändringar med mer översiktliga metoder, t.ex. punkt- och standardrutter under häckningstid (Lindström m.fl. 2012a), samt räkning av flyttande fåglar vid Ottenby (Lindström m.fl. 2012b) och Falsterbo (Karlsson m.fl. 2002, Kjellén 2011).

Vid Ottenby på Ölands södra udde har häckande och flyttande fåglar studerats årligen sedan fågelstationen grundades 1946 (Danielsson m.fl. 1947, Hjort \& Lindholm 1978, Lindström m.fl. 2012b). Sedan 1972 har en ädellövskogsyta i Ottenby lund revirkarterats årligen. Vi presenterar här resultaten av 40 års inventering av denna yta och jämför trender i fågeltätheter och artsammansättning med andra inventeringsprogram i Sverige och i utlandet.

\section{Metoder}

Provytans läge, habitat och egenskaper

Den 8,75 ha $(350 \times 250 \mathrm{~m})$ stora inventeringsytan ligger i den mellersta delen av den ca 250 ha stora lövskogen Ottenby lund, drygt $2 \mathrm{~km}$ norr om Ölands sydspets (Figur 1). Ottenby lund utgör södra Ölands största lövskog. Inventeringsrutans hörn 


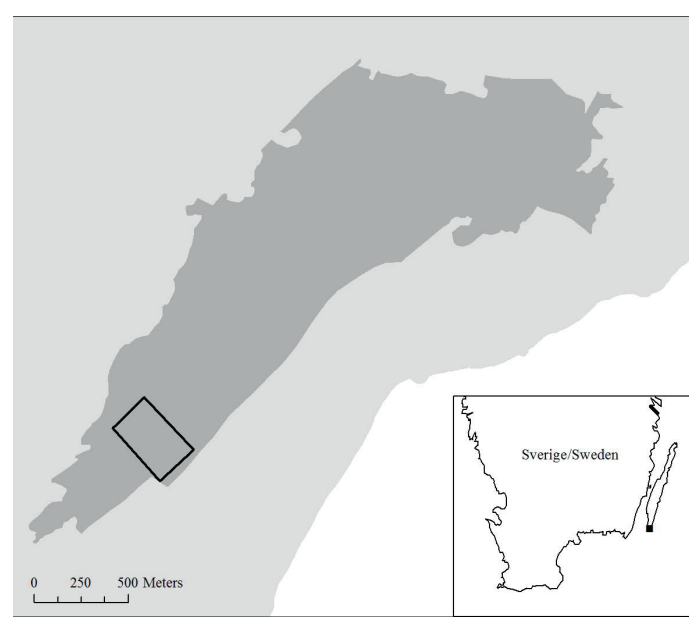

Figur 1. Inventeringsrutans position (svart rektangel) på södra Öland. Det mörkgrå området är lövskogen Ottenby lund, omgiven av i huvudsak betesmark (ljusgrått). Det vita området sydost om lunden och ängarna är Östersjön.

The position of the census plot (black square) at the southern tip of the island Öland at the Swedish Baltic coast. The dark grey area denotes the broadleaved forest "Ottenby lund", which is primarily surrounded by grazed meadows (light grey). The white area southeast of the forest and the meadows is the Baltic Sea.

har koordinaterna: $56^{\circ} 13,1249^{\prime} \mathrm{N}, 16^{\circ} 12,9574^{\prime} \mathrm{O}$; $56^{\circ} 12,9710^{\prime} \mathrm{N}, \quad 16^{\circ} 25,1973^{\prime} \mathrm{O} ; \quad 56^{\circ} 13,2122^{\prime} \mathrm{N}$, $16^{\circ} 25,1209^{\prime} \mathrm{O} ; \quad 56^{\circ} 13,0609^{\prime} \mathrm{N}, \quad 16^{\circ} 25,3731^{\prime} \mathrm{O}$. Området är naturreservat sedan 1970. Perioden 1 april - 31 augusti är det inte tillåtet för allmänheten att lämna vägar och angivna leder i området.

Habitatet i inventeringsrutan är representativt för Ottenby lund i sin helhet och består av relativt öppen lövskog dominerad av ek Quercus robur i blandade åldrar med inslag av al Alnus incatal glutinosa, asp Populus tremula och björk Betula pendula (Ekstam m.fl. 1997). Ovanligare trädslag utgörs av alm Ulmus glabra, ask Fraxinus excelsior och kastanj Castanea sativa. Ett fuktstråk i östra delen av rutan har även inslag av vide Salix $s p$. Undervegetationen består av en del hagtorn och björnbärssnår samt bräken och gräs.

\section{Inventeringsmetod}

Revirkartering har genomförts enligt Svensson (1975). Området besöks tio gånger från mitten av maj till mitten av juni. Tidpunkten har valts för att få med alla förekommande arter. Att häckningsperioden hos de närvarande arterna inte är synkroniserad påverkar i viss mån hur lätt inventeraren registrerar dem. Tidigt häckande arter, såsom bofink Fringilla coelebs och talgoxe Parus major, sjunger mer intensivt $\mathrm{i}$ april och början av maj, samtidigt som vissa långdistansflyttare, exempelvis sommargylling Oriolus oriolus, ännu inte anlänt i mitten av maj.

Vid varje inventeringstillfälle vandrade inventeraren sakta genom rutan längs linjer med $50 \mathrm{~m}$ mellanrum. Alla fågelindivider noterades samt, i synnerhet, indikationer på revir/häckning. Sjungande individer av samma art som hördes samtidigt markerades specifikt, för att särskilja närstående revir. Alla observationer bokfördes på fältkartor och informationen överfördes sedan till artkartor. Tre registreringar, eller en bekräftad boplats, krävdes för att ett permanent revir skulle bokföras. Revirkartorna har tolkats av inventeraren eller platschefen på Ottenby fågelstation, samt ungefär fram till sekelskiftet även av Sören Svensson på Ekologihuset i Lund. Denne var ansvarig för det rikstäckande inventeringsprogram av revirkarteringsytor som pågick från 1969 till mitten av 1990-talet och som Ottenby lund då ingick i (Ottosson m.fl. 2012).

Sammanlagt har 28 personer inventerat ytan i Ottenby lund under perioden 1972-2011. Dessa personer listas under Tack. Provytan inventerades även 1998, men kartmaterialet har inte gått att återfinna.

\section{Databearbetning}

De flesta jämförbara långtidsstudier behandlar enbart tättingar och antalen presenteras oftast exklusive antalet kråkfåglar. För jämförelsens skull har vi i huvudsak gjort likadant. Vi har därtill valt att beakta långdistansflyttare som en grupp, samt stannfåglar, kort- och medeldistansflyttare som en annan, givet att antalet individer från dessa två grupper kan tänkas påverkas av delvis olika processer utanför häckningstid.

Artomsättning ("species turnover rate") beräknades genom att summan av antalet nytillkomna och försvunna arter mellan två år dividerades med summan av de båda årens artantal (Svensson m.fl. 2010). Ett värde av $100 \%$ innebär att inga arter är desamma mellan två år. Vid $0 \%$ har inga förändringar skett i artsammansättningen mellan två år. För att statistiskt testa förändringar över tiden i antalet revir och arter användes Spearmans rangkorrelation $\left(\mathrm{r}_{\mathrm{s}}\right)$. Då data för 1998 saknas har vi vid trendberäkningar antagit att 1999 kommit direkt efter 1997. Med vår analysmetod, Spearmans rangkorrelation, påverkas inte resultat eller tolkningar av detta. Beräkningarna gjordes i GraphPad Prism (version 5.04 för Windows, GraphPad Software, La Jolla California USA, http://www.graphpad.com). 


\section{Resultat och diskussion \\ Fågeltäthet}

I genomsnitt registrerades 132 fågelrevir per år (samtliga arter medräknade) i Ottenby lund, vilket betyder en genomsnittlig fågeltäthet på 1509 revir/ $\mathrm{km}^{2}$. För enbart tättingar (exklusive kråkfåglar) var genomsnittet i Ottenby lund 129 revir/år, d.v.s. $1474 \mathrm{revir} / \mathrm{km}^{2}$ (Tabell 1). Denna täthet är jämförbar med den i andra liknande lövskogsområden. I Dalby Söderskog var motsvarande revirtäthet $\mathrm{i}$ genomsnitt $9 \%$ högre än i Ottenby lund (Svensson 2009) och i Sörön var den 8 \% högre (omräknat från Johannesson 2005). I Fågelsångsdalen var dock tätheten $35 \%$ lägre än i Ottenby lund (Enemar m.fl. 1994, Svensson m.fl. 2010). I den välkända lövurskogen Bialowieza National Park i Polen registrerades under åren 1995-1999 i genomsnitt $1101 \mathrm{revir} / \mathrm{km}^{2} \mathrm{i}$ den mest revirtäta biotopen dominerad av ask/al. I tre olika inventeringsrutor med ek/avenbok/lind var fågeltätheten mellan $800 \mathrm{och}$ $1000 \mathrm{revir} / \mathrm{km}^{2}$ (Wesolowski m.fl. 2002, Tomialojc \& Wesolowski 2004). Den genomsnittliga fågeltätheten i Ottenby lund och andra rika svenska lövskogar är alltså tämligen likvärdigt hög, 1000$1600 \mathrm{par} / \mathrm{km}^{2}$ (Tabell 1), och faktiskt något högre än vad som finns i den sista lilla europeiska resten av lövurskog i Polen.

Den generella fågeltätheten i Sverige är betydligt lägre än så. Ottosson m.fl. (2012) uppskattade nyligen antalet fågelpar i Sverige till 70 miljoner, vilket motsvarar i genomsnitt ungefär $170 \mathrm{par} / \mathrm{km}^{2}$ för hela Sveriges landareal $\left(410000 \mathrm{~km}^{2}\right)$. Det finns revirkarteringsdata från flera andra biotoper i Sverige. I Ammarnäs noterades i genomsnitt 403 revir/ $\mathrm{km}^{2}$ i fjällbjörkskog (Enemar m.fl. 2004), 89 revir/ $\mathrm{km}^{2}$ på lågfjällshed och $39 \mathrm{revir} / \mathrm{km}^{2}$ på högfjällshed (Svensson 2006). Barrskogar i Dalarna höll i genomsnitt 267 revir $/ \mathrm{km}^{2}$ (Forslund 2003) och i Skånes jordbruksbygder var fågeltätheten 170 re$\mathrm{vir} / \mathrm{km}^{2}$ (Svensson 2003). Mogen och av skogsbruk tämligen opåverkad lövskog är med andra ord en mycket fågelrik svensk biotop.

\section{Variation och trend $i$ fågeltäthet}

Antalet revir i Ottenby lund hade en mycket distinkt utveckling under de 40 åren (Figur 2, Tabell 2). Under de första 20 åren ökade antalet revir, om än med en liten svacka perioden 1979-1987. Under perioden 1992-2011 minskade sedan tätheten successivt för att vid periodens slut ligga på nästan samma nivå som vid inventeringens början. Denna utveckling är i stort sett omvänd mot hur antalet fåglar i Sverige förändrades under samma period (Ottvall m.fl. 2009). Perioden 1975-1995 kännetecknades i Sverige av en kraftig generell minsk-

Tabell 1. Antalet fågelarter och revir i några svenska undersökningsområden som studerats över perioder om minst 25 år. Siffrorna gäller enbart tättingar (ordning Passeriformes), dock ej kråkfåglar.

Number of species and territories of passerine birds (order Passeriformes), corvids excluded, in Swedish study sites with data covering 25 years or more.

\begin{tabular}{|c|c|c|c|c|}
\hline & $\begin{array}{l}\text { Yta } \\
\text { Area } \\
\text { (ha) }\end{array}$ & $\begin{array}{l}\text { Totalt antal arter } \\
\text { alla år } \\
\text { Total no. of } \\
\text { species all years }\end{array}$ & $\begin{array}{c}\text { Medeltal (min-max) } \\
\text { arter per år } \\
\text { Mean (min-max) } \\
\text { species per year }\end{array}$ & $\begin{array}{l}\text { Medeltal (min-max) } \\
\text { revir per km² } \\
\text { Mean (min-max) } \\
\text { territories per } \mathrm{km}^{2}\end{array}$ \\
\hline $\begin{array}{r}\text { Ammarnäs } \\
\left(65^{\circ} \mathrm{N}\right)\end{array}$ & 42 & 46 & $\begin{array}{c}27 \\
(21-34)\end{array}$ & $\begin{array}{c}403 \\
(236-564)\end{array}$ \\
\hline $\begin{array}{l}\text { Sörön }{ }^{2} \\
\qquad\left(59^{\circ} \mathrm{N}\right)\end{array}$ & 20 & 35 & - & $\begin{array}{c}1592 \\
(1386-1783)\end{array}$ \\
\hline $\begin{array}{l}\text { Ottenby }^{3} \\
\qquad\left(56^{\circ} \mathrm{N}\right)\end{array}$ & 9 & 37 & $\begin{array}{c}20 \\
(12-27)\end{array}$ & $\begin{array}{c}1474 \\
(869-2537)\end{array}$ \\
\hline $\begin{array}{l}\text { Fågelsångsdalen }{ }^{4} \\
\qquad\left(55^{\circ} \mathrm{N}\right)\end{array}$ & 13 & 41 & $\begin{array}{c}21 \\
(15-27)\end{array}$ & $\begin{array}{c}954 \\
(880-1415)\end{array}$ \\
\hline $\begin{array}{l}\text { Dalby }^{5} \\
\qquad\left(55^{\circ} \mathrm{N}\right)\end{array}$ & 37 & 32 & $\begin{array}{c}23 \\
(18-26)\end{array}$ & $\begin{array}{c}1613^{*} \\
(1443-1889)\end{array}$ \\
\hline
\end{tabular}

*Talen gäller de tre år då även stare räknades. Revirtätheten de år starar inte räknades var 833 revir $/ \mathrm{km}^{2}$ (men stare har räknats med i antalet arter för alla år).

The figure is for the three years when also Starlings were counted. The average density for years when Starlings were not counted was 833 territories $/ \mathrm{km}^{2}$ (but Starling has been included in the number of species every year).

${ }^{1}$ Enemar et al. (2004), ${ }^{2}$ Johannesson (2005), Simonsson (2008), ${ }^{3}$ This study, ${ }^{4}$ Enemar et al. (1994), Svensson et al. (2010), ${ }^{5}$ Svensson (2009). 


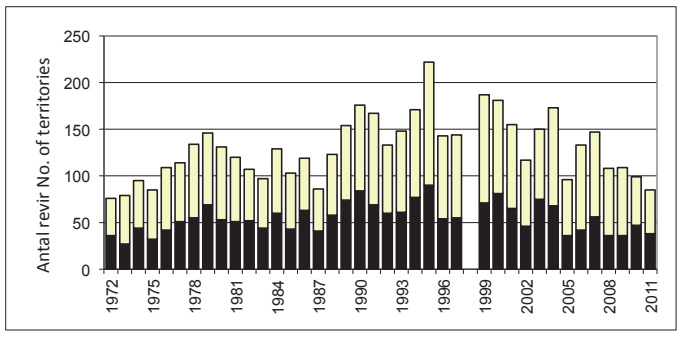

Figur 2. Antal revir (tättingar exkl. kråka) per år i inventeringsrutan i Ottenby lund 1972-2011 uppdelat på långdistansflyttare (svarta staplar) respektive stannfåglar, kort- och medeldistansflyttare (vita staplar). Det finns inga data för 1998.

Yearly number of territories (passerines, except for crow) at Ottenby 1972-2011, separated into long-distance migrants (winter outside Europe, black bars) and species wintering within Europe (white bars). There are no data for 1998.

ning av antalet fåglar. Omvänt, när fågelantalen därefter minskade kraftigt i Ottenby lund, var de svenska fågelantalen stabila eller till och med något ökande (Ottvall m.fl. 2009).

Även för de andra lokalerna med långa tidsserier var trenderna för ungefär samma tidsperiod olika, både sinsemellan och jämfört med Sverige i stort. I Fågelsångsdalen ökade antalet revir under perioden 1972-2009 (Svensson m.fl. 2010), medan fågelsamhällena i Dalby Söderskog och Ammarnäs inte visade någon klar trend över perioderna 1980 2006 (Svensson 2009) respektive 1972-1999 (Enemar m.fl. 2004). Detta visar tydligt att trenden i antalet fåglar på en given plats, kan vara tämligen oberoende av storskaliga förändringar, även när ha- bitatet till synes varit ganska oförändrat.

Mellanårsvariationen i antalet revir i Ottenby lund är större än i andra långtidsserier. Det maximala antalet småfågelrevir överstiger minimiantalet med $192 \%$ (146 \% borträknat extremvärdet från år 1995), att jämföra med 139 \% i Ammarnäs (Enemar m.fl. 2004), 77 \% i Fågelsångsdalen (Svensson m.fl. 2010) och $44 \%$ i Bialowieza (Wesolowski m.fl. 2002). Den högsta ökningen mellan två på varandra följande år var emellertid bara $36 \%$ i Ottenby lund, vilket är mindre än de $60 \%$ och $39 \%$ som registrerats i Ammarnäs respektive Fågelsångsdalen. Motsvarande värde i Bialowieza var $13 \%$ (Wesolowski m.fl. 2002). I stort sett faller värdena in i det generella mönstret att mellanårsvariationen i fågeltäthet ökar med ökande latitud (Järvinen 1979).

\section{Variation och omsättning $i$ artantal}

Det årliga antalet fågelarter i provytan i Ottenby lund fluktuerade mellan 13 och 33 (medel 22). Medel för antalet tättingarter (utom kråka) i Ottenby lund var 20. Totalt har 51 arter registrerats som revirhävdande i Ottenby lund, 37 arter tättingar (utom kråka). Motsvarande siffror för fyra andra lövskogsområden i Sverige är generellt mycket lika (Tabell 1), trots att såväl provytans storlek, tidsseriens längd och totala antalet revir borde påverka värdena.

Omsättningen av arter, här beräknat som "species turnover" mellan på varandra följande år, varierade mellan $3 \%$ och $26 \%$ i småfågelsamhället i Ottenby lund (medel $14 \%$ ), utan nämnvärda skill-

Tabell 2. Trender i antal arter och revir av tättingar (exkl. kråka) i Ottenby lund uppdelat på två 20-årsperioder. Värdena som anges är korrelationskoefficienten från Spearmans rangkorrelation. Ett negativt värde anger en minskning över tiden.

Trends in number of species and territories of passerines (except crow) at Ottenby during two time periods. The values shown are Spearman correlation coefficients. A negative value means a decrease over time.

\begin{tabular}{llcc}
\hline & Total & Period 1 & Period 2 \\
& $1972-2011$ & $1972-1991$ & $1992-2011$ \\
\hline $\begin{array}{l}\text { Totalt antal revir } \\
\begin{array}{l}\text { Total no. of territories } \\
\text { Antal revir långdistansflyttare }\end{array}\end{array}$ & $0,316(\mathrm{~ns})$ & $0,615(* *)$ & $-0,599(* *)$ \\
$\begin{array}{l}\text { No. of territories long-distance migrants } \\
\text { Antal revir kortdistansflyttare }\end{array}$ & $0,147(\mathrm{~ns})$ & $0,678(* *)$ & $-0,633(* *)$ \\
$\begin{array}{l}\text { No. of territories short-distance migrants } \\
\text { Totalt antal arter }\end{array}$ & $0,396(*)$ & $0,514(*)$ & $-0,472(*)$ \\
$\begin{array}{l}\text { Total no. of species } \\
\text { Antal arter långdistansflyttare }\end{array}$ & $0,127(\mathrm{~ns})$ & $0,477(*)$ & $-0,841(* * *)$ \\
$\begin{array}{l}\text { No. of long-distance migrant species } \\
\text { Antal arter kortdistansflyttare }\end{array}$ & $-0,237(\mathrm{~ns})$ & $0,430(\mathrm{~ns})$ & $-0,860(* * *)$ \\
No. of short-distance migrant species & $0,446(* *)$ & $0,404(\mathrm{~ns})$ & $-0,643(* *)$ \\
\hline
\end{tabular}


nader mellan olika artkategorier. Fågelsångsdalen uppvisar ett något lägre medel, $11 \%$ (2-25\%, Svensson m.fl. 2010). Ammarnäs hade generellt högre omsättning, i genomsnitt $30 \%(8-37 \%)$, vilket stämmer med hypotesen att variationen $\mathrm{i}$ omsättning av arter ("species turnover") är större på nordligare breddgrader (Enemar m.fl. 2004, Järvinen 1979).

\section{Möjliga lokala orsaker till variation $i$ antal revir och arter $i$ Ottenby lund}

Den höga variationen i antalet revir i inventeringsrutan i Ottenby lund är förvånande med tanke på att mycket rika habitat $i$ ett sent skede av successionen generellt förväntas vara mättade (Fretwell \& Lucas 1970). Det finns i våra ögon inga habitatförändringar som tydligt kan förklara den stora variationen, men någon systematisk dokumentation av habitatförändringar inom inventeringsrutan har tyvärr inte gjorts.

Dovhjortar Dama dama och kor har förekommit tämligen talrikt vilket medför att undervegetationen hållits nere. Antalet djur har emellertid varierat en hel del (von Schultz 1995). Idag (2012) uppskattas vinterstammen av dovhjort till ca 200 djur (tillsyningsman Johan Parboäng, muntligen). Under 1990-talet kan antalet ha varit så högt som 300-350 djur. Närvaron av kor i Ottenby lund har skiftat än mer, från inga alls under många år till omfattande skogsbete, exempelvis 70 kor med kalvar i maj samt 200 dikor i oktober 2006-2008 (arrendator Andreas Wiström, muntligen).

Hela Ottenby lund har en särskild skötselplan inom naturreservatet Ottenby. Ett visst uttag av virke samt röjning av sly har gjorts vid några tillfällen, bl.a. togs ca 600 ekar ur lunden under 1980och 1990-talen. Runt år 2000 drabbades dessutom många ekar i Ottenby lund av "eksjukan" eller "ekdöden" (reservatsansvarig Håkan Lundkvist, muntligen), men hur detta påverkat fåglarna är okänt.

Vår uppfattning är att biotopvariationen totalt sett har varit relativt liten och att de skillnader som förekommit framför allt gällt undervegetationen. På lång sikt torde den högre växtligheten, trots ingrepp, angrepp och naturlig succession, varit förhållandevis konstant. Rutans sydöstra hörn gränsar till de öppna landskap som omger Ottenby lund, vilket emellertid inte verkar ge upphov till uppenbara "kanteffekter". Således förekommer inga arter utöver de som trivs inne i den relativt slutna skogsbiotop som Ottenby lund mestadels består av.

Ytterligare en faktor värd att nämna är antalet predatorer. Sedan rödräven Vulpes vulpes under 1990-talet i stort sett utrotats av rävskabb har grävling Meles meles och mård Martes martes blivit talrika i Ottenby lund (tillsyningsman Johan Parboäng, muntligen). Grävlingen torde främst utgöra ett hot mot markhäckare som lövsångare Phylloscopus trochilus, medan mården sannolikt kan ha en betydande inverkan på antalet tättingar som blir flygga.

Ett stort antal olika inventerare (28) har sannolikt bidragit i någon mån till variationen. Den största förändringen $\mathrm{i}$ antalet revir mellan på varandra följande år var emellertid mindre i Ottenby lund jämfört med i Fågelsångsdalen och i Ammarnäs, där betydligt färre inventerare varit involverade.

\section{Lång- och kortdistansflyttare}

Långdistansflyttarna är en grupp arter som det under de senaste decennierna gått jämförelsevis dåligt för, både i Sverige (Ottvall m.fl. 2009) och i övriga Europa (Sanderson m.fl. 2006). Detta skulle kunna bero på försämrade förhållanden i övervintringsområdena, men det har också föreslagits att de påverkats av populationsutvecklingen hos kortdistansflyttare (och stannfåglar). På grund av successivt mildare vintrar ökar antalet individer av de köldkänsliga kortdistansflyttarna och långdistansflyttarna får därmed allt svårare att finna någonstans att slå sig ner när de anländer sent på våren (Herrera 1978, O'Connor 1981, Enemar m.fl. 1994). Vi undersökte därför hur det gått för gruppen långdistansflyttare $\mathrm{i}$ Ottenby lund och jämförde med andra långtidsstudier i Sverige.

Av de 37 förekommande tättingarterna i Ottenby lund är 20 långdistansflyttare (54\%) och 17 stannar i Europa (vi inkluderar alltså även stannfåglar i termen "kortdistansflyttare"). Det genomsnittliga antalet revir för långdistansflyttarna var 54 och kortdistansflyttarna 75 (Figur 2). Räknat per år har långdistansflyttarna $\mathrm{i}$ genomsnitt utgjort $42 \% \mathrm{av}$ reviren (variation 32-53 \%). Proportionen långdistansflyttare har inte ändrats i någon entydig riktning över åren $\left(r_{\mathrm{s}}=-0,275, \mathrm{p}=0,09\right)$, men den ökade något fram till 1986 för att därefter generellt minska (Appendix 1). Både för kort- och långdistansflyttare ökade antalet revir fram till mitten på 1990-talet, för att därefter minska och 2011 nå liknande nivåer som 40 år tidigare (Tabell 2, Figur 2). Det fanns en starkt positiv korrelation mellan antalet revir av de båda grupperna $\left(r_{s}=0,73, p<0,001\right.$, Figur 3$)$. Med andra ord, de år det fanns många kortdistansflyttare i Ottenby lund så fanns det också många långdistansflyttare där och vice versa.

I Bialowieza i Polen utgjorde långdistansflyttar- 


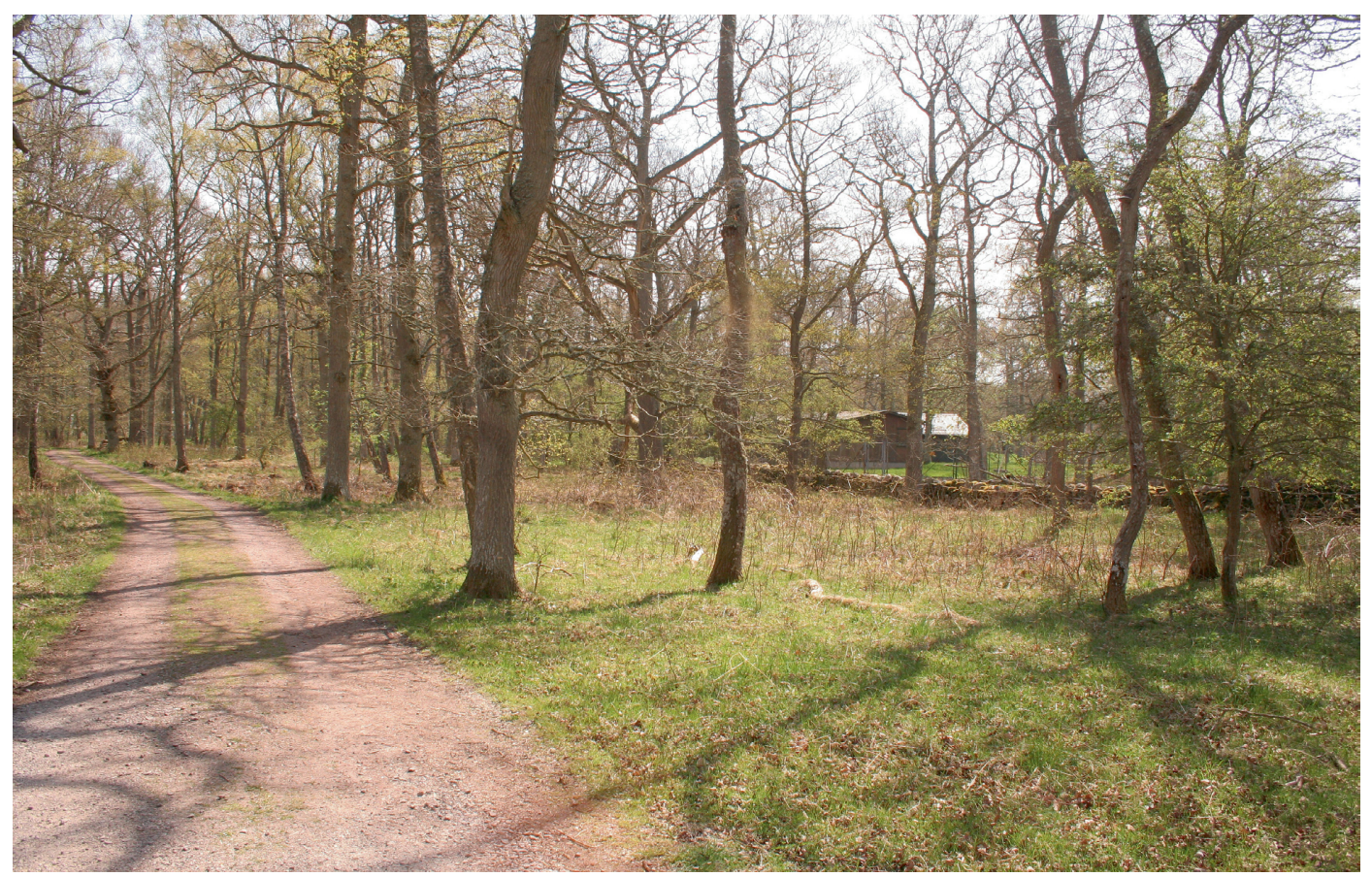

Bild 1. Några grusvägar genomkorsar inventeringsrutan, just denna väg sträcker sig österut från rutans sydvästra hörn.

Bilden tagen 9 maj 2012.

A few dirt roads cross the census plot. Picture taken 9 May 2012.

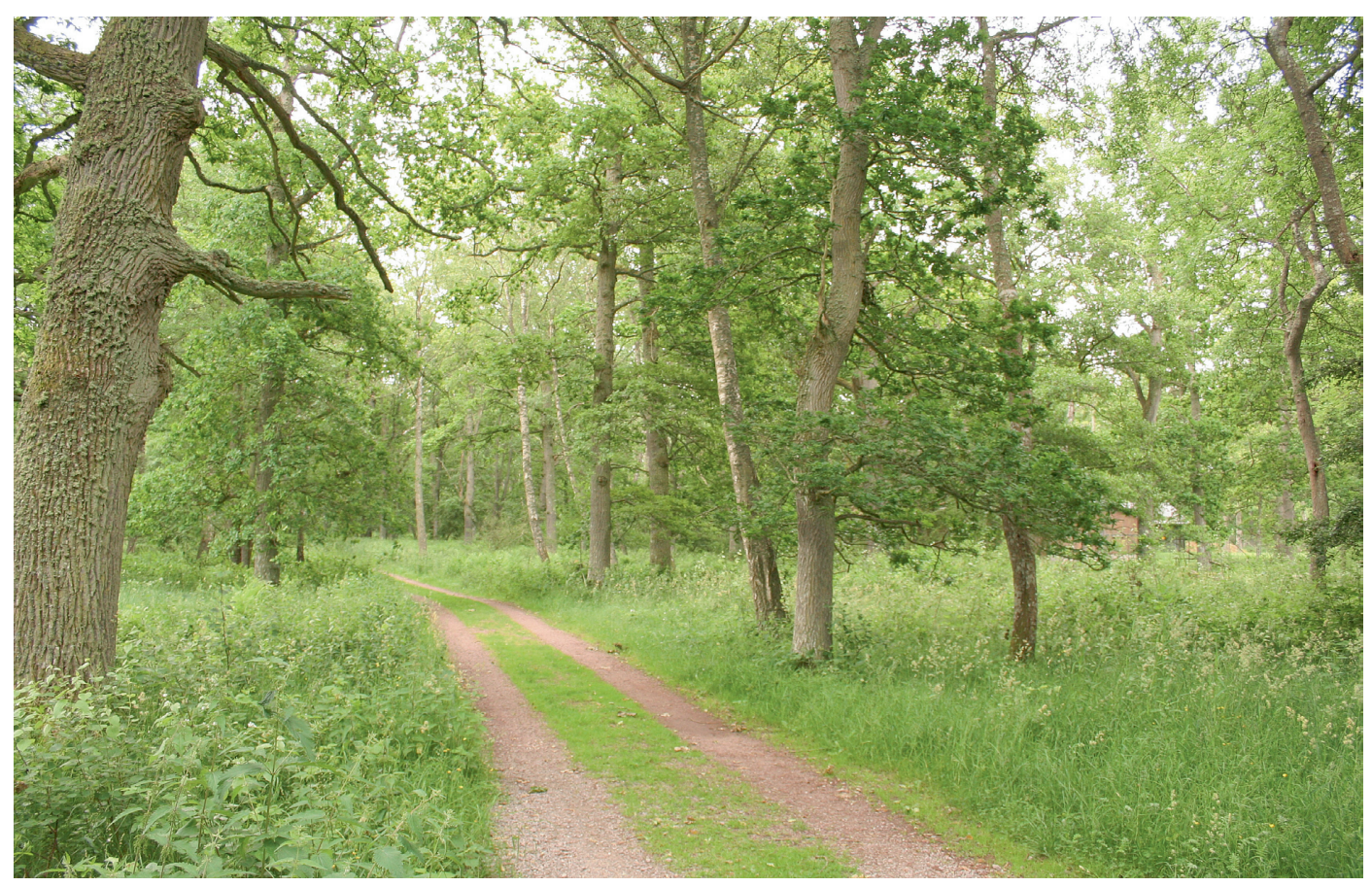

Bild 2. Samma motiv som bild 1, nu med fullt utvecklat lövverk och frodig undervegetation. Bilden tagen 5 juli 2012.

Same site as above, now with fully developed vegetation. Picture taken 5 July 2012. 


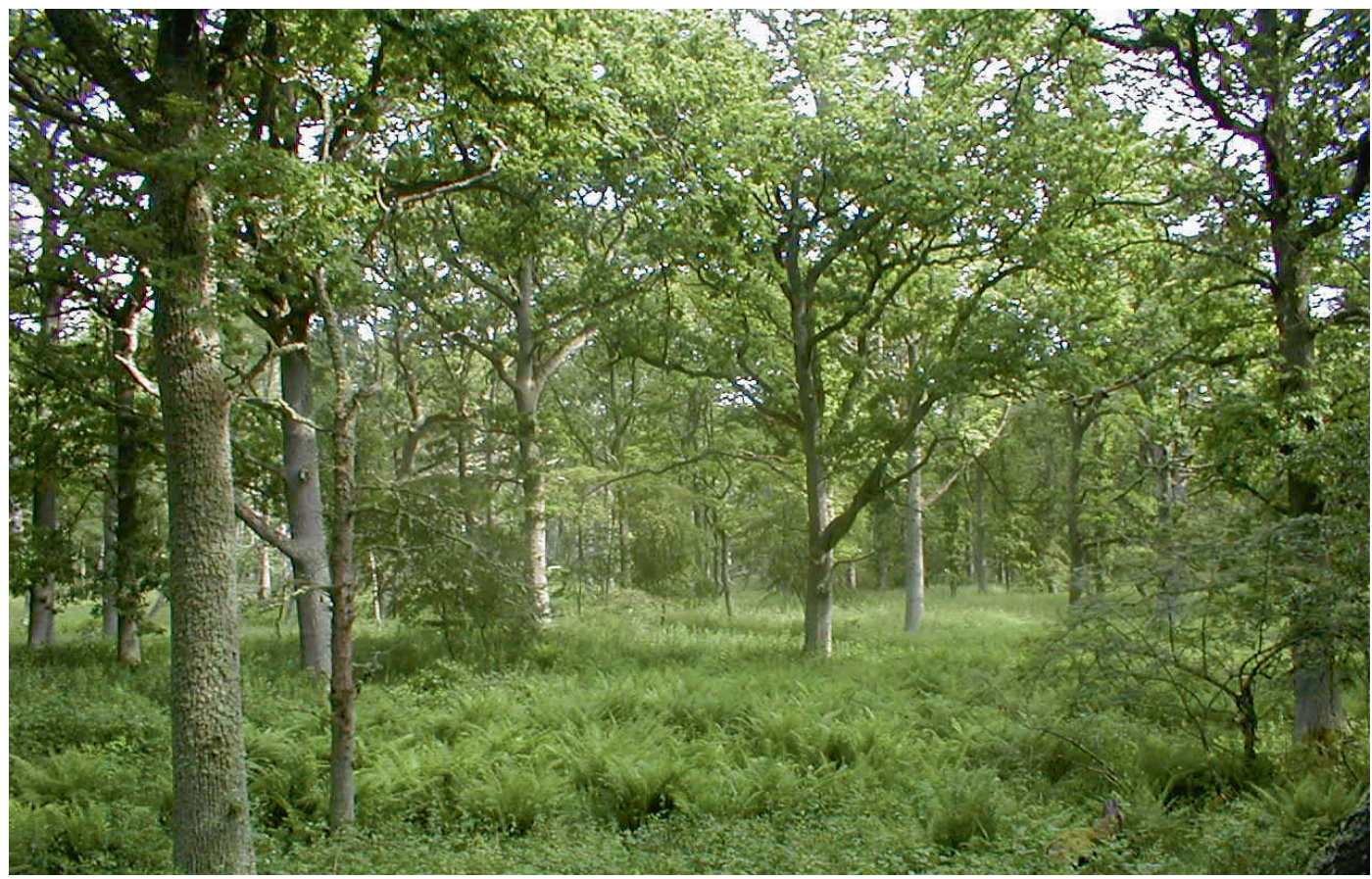

Bild 3. Den för inventeringsrutan så typiska öppna ekskogen, med undervegetation av bräken. Bilden tagen sommaren 2001. Typical open oak forest. Picture taken in the summer of 2001.

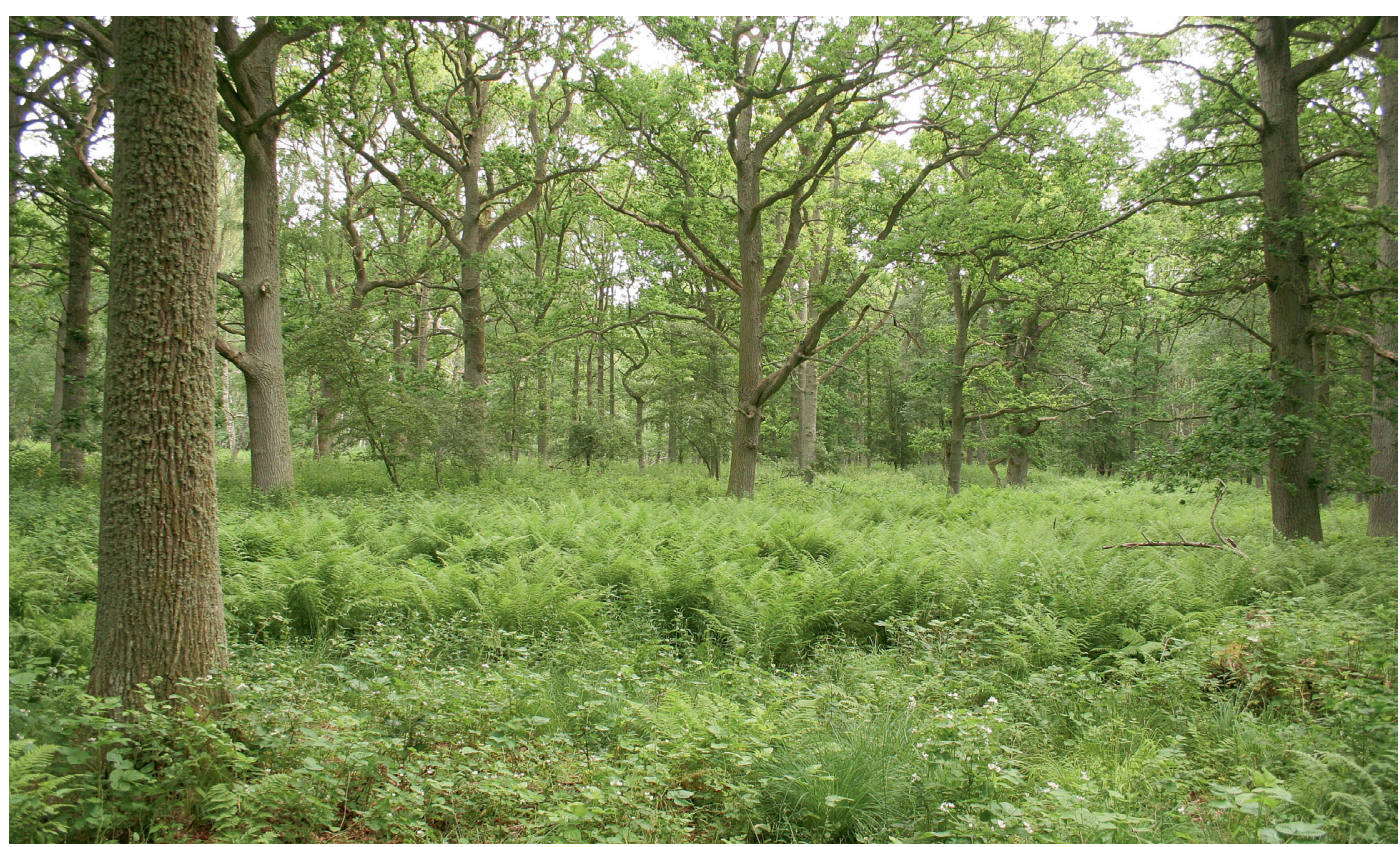

Bild 4. Samma motiv som bild 3, men tagen 11 år senare (5 juli 2012). Notera att en del mindre träd och buskar tagits bort sedan 2001.

The same site as above, but picture taken 11 years later when some smaller trees and bushes have been removed. Picture taken 5 July 2012. 


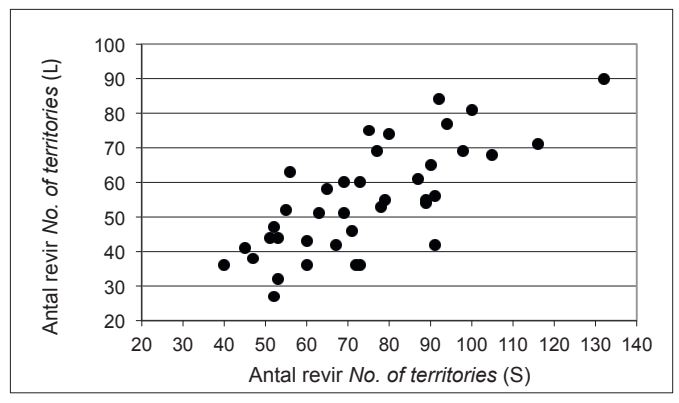

Figur 3. Sambandet mellan antalet revir av lång- (L) respektive kortdistansflyttare (S) i inventeringsrutan i Ottenby lund 1972-2011.

The relationship between the number of territories of shortand long-distance migrant passerine species at Ottenby 1972-2011.

na endast $25 \%$ av det totala antalet revirhållande individer, medan motsvarande siffror för Ottenby lund var $42 \%$, Fågelsångsdalen $47 \%$ och Ammarnäs $50 \%$. Detta stämmer tämligen väl överens med hypotesen att proportionen långdistansflyttare ökar med ökande breddgrad (Herrera 1978, O'Connor 1981). Notera dock att i Fågelsångsdalen minskade andelen långdistansflyttare kraftigt under undersökningsperioden, från ungefär $60 \%$ under tidigt 1950-tal till bara ungefär $38 \%$ knappt 60 år senare (Svensson m.fl. 2010).

Både i Ottenby lund och i Ammarnäs fanns en positiv korrelation mellan antalet kort- och långdistansflyttare, medan korrelationen i Fågelsångsdalen var negativ. För den sistnämnda lokalen har det föreslagits att det negativa sambandet skulle kunna bero på konkurrens mellan grupperna (Enemar m.fl. 1994). Detta skulle då också kunna förklara den långsiktiga minskningen i proportionen långdistansflyttare i Fågelsångsdalen. Denna förklaring lär dock inte gälla för Ottenby lund och Ammarnäs. Fågelsamhället i Ammarnäs har antagits vara omättat, antagligen på grund av stor vädervariation som hindrar samhället att uppnå sitt "carrying capacity" (Enemar m.fl. 2004). Att detta skulle gälla även för det mycket fågeltäta Ottenby lund är nog mindre sannolikt. Samvariationen mellan antalet lång- och kortdistansflyttare i Ottenby lund indikerar att det är lokala faktorer som bestämmer det häckande beståndets storlek ett givet år.

Den årliga andelen långdistansflyttande arter bland tättingarna i Ottenby lund har varierat stort (35-67 \%). Likt mönstret för antalet revir så ökade antalet arter både hos lång- och kortdistansflyttarna fram till mitten på 1990-talet, för att därefter minska och 2011 nå liknande nivåer som 40 år tidigare (Tabell 2, Figur 4).

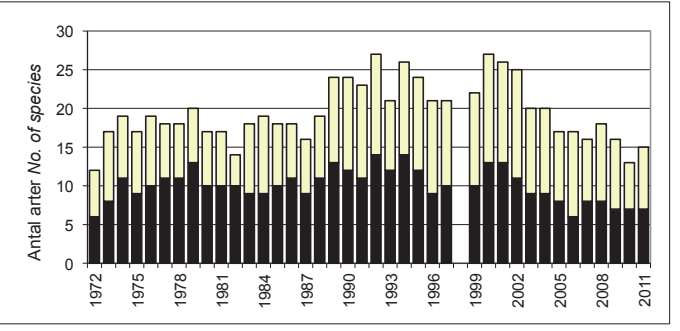

Figur 4. Antal arter (tättingar exkl. kråka) per år i inventeringsrutan i Ottenby lund 1972-2011 uppdelat på långdistansflyttare (svarta staplar) respektive stannfåglar, kort- och medeldistansflyttare (vita staplar). Det finns inga data för 1998.

Yearly species number (passerines, except for crow) at Ottenby 1972-2011, separated into long-distance migrants (winter outside Europe, black bars) and species wintering within Europe (white bars). There are no data for 1998.

\section{Enskilda arter}

Här följer en kort genomgång av några enskilda arters förekomst och trender. Jämförelser görs främst med de nationella trenderna i Sverige, så som de framgår av de fria punktrutterna inom Svensk fågeltaxering (Lindström m.fl. 2012a). Dessa rutter täcker perioden 1975-2011 och gäller i huvudsak Sydsverige. För jämförelsens skull har vi beräknat trender över tiden med Spearmans rangkorrelation, både för antalet revir vid Ottenby och för årsindex för punktrutterna. De enskilda arternas årliga antal presenteras i Appendix 1.

De flesta fågelsamhällen i tempererade områden karakteriseras av några få mycket vanliga arter samt många mindre vanliga arter (Svensson 2006). Detta gäller även för Ottenby lund. Bofink och lövsångare har tillsammans utgjort i genomsnitt $40 \%$ av antalet par i Ottenby lund (24-52\%). Proportionen är som väntat högre än den för Sverige i sin helhet, där de två arterna tillsammans utgör $31 \%$ av alla fåglar (Ottosson m.fl. 2012). I Ammarnäs är dock dominansen för de två talrikaste arterna $\mathrm{i}$ fjällbjörkskogen, d.v.s. lövsångare och bergfink Fringilla montifringilla, ännu större. Dessa två arter utgjorde uppemot $60 \%$ av fågelparen där (Enemar m.fl. 2004).

Bara sex arter har funnits representerade alla år i Ottenby lund. Förutom bofink och lövsångare är det trädpiplärka Anthus trivialis, härmsångare Hippolais icterina, trädgårdssångare Sylvia borin och grå flugsnappare Muscicapa striata. Bortsett från enstaka år (1-3) har även koltrast Turdus merula, svarthätta Sylvia atricapilla, grönsångare Phylloscopus sibilatrix, blåmes Cyanistes caeruleus, talgoxe, trädkrypare Certhia familiaris och stare Sturnus vulgaris häckat årligen. 
Trenderna för dessa tretton arter vid Ottenby överensstämde inte med trenderna för Sverige i övrigt $\left(r_{\mathrm{s}}=0,203, \mathrm{p}=0,50\right)$. Det som hänt en art $\mathrm{i}$ Sverige $i$ stort har alltså inte nödvändigtvis skett $i$ Ottenby lund. I Ottenby lund var det dock bara tre arter som uppvisade signifikanta förändringar i antal över de 40 åren. Alla tre ökade i antal: svarthätta $\left(r_{\mathrm{s}}=0,44, \mathrm{p}=0,005\right)$, trädgårdssångare $\left(\mathrm{r}_{\mathrm{s}}=0,42\right.$, $\mathrm{p}=0,008)$ och stare $(\mathrm{r}=0,40, \mathrm{p}=0,011)$. Alla dessa tre hade en topp runt år 2000 och har uppträtt i lägre antal därefter.

Den utan tvekan dominerande arten i Ottenby lund är bofinken. Arten får anses ha varit relativt stabil under den aktuella 40-årsperioden, även om en viss minskning har skett på senare år. I Sverige har arten minskat svagt men tydligt på punktrutterna.

Lövsångaren (av den sydliga rasen trochilus), som ibland varit nästan lika talrik som bofinken, hade länge en positiv trend i Ottenby lund. Denna bröts dock abrupt med en drastisk minskning i mitten av 2000-talet. Även på punktrutterna har arten minskat i antal.

Två arter har ökat långsiktigt $\mathrm{i}$ antal både i Ottenby lund och i Sverige, nämligen blåmes och svarthätta, och en art har minskat långsiktigt, nämligen trädpiplärka. Den senare var som talrikast i Ottenby lund 1987-1991, men verkar nu ha stabiliserat sig på samma låga nivå som på 1970-talet.

För två andra arter pekar trenderna i motsatt riktning. Koltrasten har ökat i antal i Sverige, medan trenden i Ottenby lund är svagt negativ. Staren, en av landets stora förlorare de senaste decennierna, har haft en signifikant stigande trend i Ottenby lund. Staren var under ett par år på 1990-talet faktiskt den talrikaste häckfågeln $\mathrm{i}$ inventeringsrutan i Ottenby lund. Den långsiktigt positiva trenden till trots har dock arten minskat betydligt $\mathrm{i}$ antal de senaste 10 åren.

Flera arter har vandrat in och etablerat sig i området under de 40 studieåren. Gärdsmygen Troglodytes troglodytes häckade knappt alls de första femton åren, men har sedan etablerat en stabil population med upp till 9 revir. Arten har, till följd av förhöjd överlevnad under milda vintrar, ökat kraftigt som häckfågel i Sverige under 2000-talet. Under ett par stränga vintrar i slutet av undersökningsperioden decimerades emellertid den svenska stammen kraftigt, så även i Ottenby lund. Den sydliga gransångaren Phylloscopus c. collybita är en annan sentida invandrare som förekom i stort sett årligen i rutan med 1-3 revir under åren 1985-1999. Med tanke på artens enorma sentida expansion i Sydsverige är det därför märkligt att ingen fågel hållit revir 2005-2011. Gulsparven häckade för första gången i området 1988 för att därefter ha varit nästan årlig, med som mest 7 par. Arten har däremot minskat i Sverige under samma period. Nötväckan, som långsiktigt ökat i Sverige, registrerades första gången som häckfågel i Ottenbyrutan 1990, och har sedan dess förekommit de flesta år med 1-2 par.

Det finns ingen vanlig art som försvunnit under de 40 åren, men man kan notera att ringduva, sädesärla, björktrast, taltrast och svartvit flugsnappare setts fåtaligt, om alls, de senaste tio åren.

\section{Slutsats}

Antalet revir i Ottenby lund har i genomsnitt varit mycket högt, runt $1500 \mathrm{par} / \mathrm{km}^{2}$, vilket befäster bilden av ädellövskogen som en av våra mest fågelrika biotoper. Förändringen i antal revir över tiden, med en generell ökning under de första 20 åren, följt av en generell minskning de senaste 20 åren, följer inte den generella trenden i Sverige. Likaså för enskilda arter följer trenderna i Ottenby lund inte de nationella trenderna. Proportionen långdistansflyttare förändrade sig inte på något markant sätt över åren. Var det många kortdistansflyttare i undersökningsområdet var det också många långdistansflyttare. Detta antyder att långdistansflyttarna som grupp inte missgynnats och att de inte heller påverkas negativt av antalet kortdistansflyttare.

\section{Tack}

Följande personer inventerade provytan i Ottenby lund mellan 1972 och 2011: Holger Stenson och Claes-Göran Lindholm (1972), Christer Wahlström (1973), Göran Cederwall (1973-1974), Jan Österberg (1975), Björn Sandgren (1976), Göran Wallinder (1977-1982), Lars-Åke Persson (1983), Daniel Green (1984-1985), Mårten Hammar (1986), Peter Sieurin (1987), Ulf Ottosson (1988), Kristian Johansson (1988 och 1990), Johan Engström (1989), Jakob Lohm (1991), Tommie Skoog (1992), Niklas Holmqvist (1993), Thomas Ewerlid (1994), Patrik Rhönnstad (1994-1995), Richard Ottvall (19961997), Daniel Bengtsson (1999-2001), Martin Stervander (2001), Mattias Ullman (2002), Andreas Wedman (2003), Gabriel Norevik (2004-2006 och 2008), Ronny Malm (2007), Magnus Bladh 2009 samt Linus Hedh 2010-2011. Ett stort och varmt tack till alla dessa, samt till Gabriel Norevik för hjälp med framtagande av kartmaterial. Detta är meddelande no. 265 från Ottenby Fågelstation. 


\section{Referenser}

Anon. 1970. Recommendations for an international standard for a mapping method in bird census work. Pp. 49-52 in Bird census work and environmental monitoring (Svensson, S. ed.). Bull. Ecol. Res. Comm. Nr 9. Lund.

Danielsson, G., Edelstam, C. \& Svärdson, G. 1947. Ottenby fågelstation, dess tillkomst och verksamhet år 1946. Vår Fågelvärld 6: 38-51.

Ekstam, U., Forshed, N. \& Johansson, O. 1997. Ottenby: naturen och historien. Länsstyrelsen i Kalmar län.

Enemar, A., Cavallin, B., Nyholm, E., Rudebeck, I. \& Thorner, A.M. 1994. Dynamics of a passerine bird community in a small deciduous wood, S Sweden, during 40 years. Ornis Svecica 4: 65-104.

Enemar, A., Sjöstrand, B., Andersson, G. \& Proschwitz, T. von. 2004. The 37-year dynamics of a subalpine passerine bird community, with special emphasis on the influence of environmental temperature and Epirrita autumnata cycles. Ornis Svecica 14: 63-106.

Enemar, A. \& Thorner, A.M. 2003. Fågelsångsdalen 50 år. Anser 42: 18-23.

Forslund, M. 2003. Fågelfaunan i olika skogsmiljöer - en studie på beståndsnivå. Skogsstyrelsens rapportserie nr. 2003:2.

Fretwell, S.D. \& Lucas, H.L., Jr. 1970. On territorial behavior and other factors influencing habitat distribution in birds. I. Theoretical Development. Acta Biotheoretica 19: $16-36$.

Herrera, C.M. 1978. On the breeding distribution patterns of European migrant birds: MacArthur's theme re-examined. Auk 95: 496-509.

Hjort, C. \& Lindholm, C.-G. 1978. Annual bird ringing totals and population fluctuations. Oikos 30: 387-392.

Johannesson, H. 2005. Häckfågeltaxeringen i Sörön 2004. Fåglar i Kvismaren 20: 33-38.

Järvinen, O. 1979. Geographical gradients of stability in European bird communities. Oecologia 38: 51-69.

Karlsson, L., Ehnbom, S., Persson, K. \& Walinder, G. 2002. Changes in numbers of migrating birds at Falsterbo, South Sweden, during 1980-1999, as reflected by ringing totals. Ornis Svecica 12: 113-137.

Kjellén, N. 2011. Sträckfågelräkningar vid Falsterbo hösten 2010. Fåglar i Skåne 2010: 5-42.

Lindström, Å., Andersson, A., Danielsson, M., Hellström, M. \& Waldenström, J. 2012b. Fågelräkning och ringmärkning vid Ottenby 2011. Rapport, Ottenby fågelstation. 44 pp.

Lindström, Å., Green, M. \& Ottvall, R. 2012a. Övervakning av fåglarnas populationsutveckling. Arsrapport för 2011. Rapport, Biologiska institutionen, Lunds Universitet. 82 pp.

O’Connor, R.J. 1981. Comparisons between migrant and non-migrant birds in Britain. Pp. 157-195 in Animal Migration (Aidley, D.E. ed.). Cambridge University Press.

Ottosson, U., Ottvall, R., Elmberg, J., Green, M., Gustafsson, R., Haas, F., Holmqvist, N., Lindström, Å., Nilsson, L., Svensson, M., Svensson, S. \& Tjernberg, M. 2012. Fåglarna i Sverige - antal och förekomst. SOF, Halmstad.

Ottvall, R., Edenius, L., Elmberg, J., Engström, H., Green, M., Holmqvist, N., Lindström, Å., Tjernberg, M. \& Pärt, T. 2009. Population trends for Swedish breeding birds. Ornis Svecica 19:117-192
Sanderson, F.J., Donald, P.F., Pain, D.J., Burfield, I.J., van Bommel, F.P.J. 2006. Long-term population declines in Afro-Palearctic migrant birds. Biological Conservation 131: 93-105.

Simonsson, P. 2008. Häckfågeltaxeringen vid Sörön 2007. Fåglar i Kvismaren 23: 28-30.

Svensson, S. 1975. Handledning för Svenska Häckfågeltaxeringen med beskrivningar av revirkarteringsmetoden och punkttaxeringsmetoden. Zoologiska institutionen, Lunds universitet.

Svensson, S. 2003. Övervakningsprogram för jordbrukslandskapets fåglar i Skåne. Arsrapport för 2002. Rapport nr 2003:40, Länsstyrelsen i Skåne län.

Svensson, S. 2006. Species composition and population fluctuations of alpine bird communities during 38 years in the Scandinavian mountain range. Ornis Svecica 16: $183-210$.

Svensson, S. 2009. A stable bird community during 27 years (1980-2006) in the nemoral broadleaf wood Dalby Söderskog National Park. Ornis Svecica 19: 237-243.

Svensson, S., Thorner, A.M. \& Nyholm, N.E.I. 2010. Species trends, turnover and composition of a woodland bird community in southern Sweden during a period of fiftyseven years. Ornis Svecica 20: 31-44.

Thorner, A.M. 2004. Fågelsångsdalen 2004: 200 revir - högsta någonsin. Anser 43: 151-153.

Thorner, A.M. 2007. Fågelsångsdalen 2007 - näktergal och gransångare befäster sina ställningar. Anser 46: 169 .

Tomialojc, L. \& Wesolowski, T. 2004. Diversity of the Bialowieza Forest avifauna in space and time. Journal Ornithology 145: 81-92.

Wesolowski, T. \& Tomialojc, L. 1997. Breeding bird dynamics in a primeval temperate forest: long-term trends in Bialowieza National Park (Poland). Ecography 20: 412-453.

Wesolowski, T., Tomialojc, L., Mitrus, C., Rowinski, P. \& Czeszczewik, D. 2002. The breeding bird community of a primeval temperate forest (Bialowieza National Park, Poland) at the end of the 20th century. Acta Ornithologica 37: $28-45$.

Wesolowski, T. 2003. Bird community dynamics in a primeval forest - is interspecific competition important? Ornis Hungarica 12-13: 51-62.

Wretenberg, J., Lindström, Å., Svensson, S., Thierfelder, T. \& Pärt, T. 2006. Population trends of farmland birds in Sweden and England - similar trends but different patterns of agricultural intensification. Journal of Applied Ecology 43: 1110-1120.

Von Schultz, R. 1995. Ottenby Kunglig jaktpark - 25 års viltvård. Rapport nr 12 från Ottenby fågelstation (96 sidor).

\section{Summary}

Several series of standardised long-term bird surveys exist in Sweden. Through territory mapping, based on repeated visits during spring, the number of territories per species in a specific area is determined. The longest unbroken series comes from Scania, southernmost Sweden, where Fågelsångsdalen ("Bird Song Valley") has been surveyed on 
an annual basis since 1953 (Enemar et al. 1994, Enemar \& Thorner 2003, Thorner 2004, 2007, Svensson et al. 2010). Other similar studies have been carried out near Ammarnäs, southern Lappland, in subalpine birch forest (since 1963, Enemar et al. 2004) and on upland tundra (since 1964, Svensson 2006), in the broadleaved forest Sörön, mid-Sweden (since 1965, Johannesson 2005, Simonsson 2008), and in Dalby Söderskog, Scania (15 seasons over 27 years 1980-2006, Svensson 2009).

At the national level, Swedish bird populations are monitored by point counts and line transects (Lindström et al. 2012a), as well as with standardised counting of migrating birds at important migration sites such as Ottenby (Lindström et al. 2012b) and Falsterbo (Karlsson et al. 2002, Kjellén 2011).

At Ottenby, on the southernmost tip of Öland in the Baltic Sea, breeding and migrating birds have been studied yearly since the bird observatory was founded in 1946 (Danielsson et al. 1947, Hjort \& Lindholm 1978, Lindström et al. 2012b). Each year since 1972, the number of territories and species in a designated area in the rich broadleaved forest of Ottenby lund has been studied. The results are presented here, and compared with similar studies in Sweden and Poland.

\section{Location, habitat and properties of the study site}

The study site is a $350 \times 250 \mathrm{~m}$ square in the middle part of the $2.5 \mathrm{~km}^{2}$ broadleaved forest of Ottenby lund, approximately $2 \mathrm{~km}$ north of the southernmost tip of Öland (Figure 1). The corner coordinates are: $56^{\circ} 13,1249^{\prime} \mathrm{N}, 16^{\circ} 12,9574^{\prime} \mathrm{E}$; $56^{\circ} 12,9710^{\prime} \mathrm{N}, \quad 16^{\circ} 25,1973^{\prime} \mathrm{E} ; \quad 56^{\circ} 13,2122^{\prime} \mathrm{N}$, $16^{\circ} 25,1209^{\prime} \mathrm{E} ; 56^{\circ} 13,0609^{\prime} \mathrm{N}, 1^{\circ} 25,3731^{\prime} \mathrm{E}$. Ottenby lund is a designated nature reserve and from the 1st of April through August the public is not allowed to walk outside roads and signed tracks in the area.

The habitat is representative for Ottenby lund, being open and dominated by oak Quercus robur of varying ages. Alder Alnus incata/glutinosa, aspen Populus tremula and birch Betula pendula are also important elements (Ekstam et al. 1997). Willows Salix sp. occur in wetter parts and the understory vegetation consists mainly of hawthorn, blackberry, bracken and grass.

\section{Survey method}

Territory mapping has been carried out according to Svensson (1975). The area is visited ten times from mid-May to mid-June. The mapping period has been chosen so that all species that occur in the plot have arrived to their breeding sites. On each visit, the observer slowly walks along a grid system of lines $50 \mathrm{~m}$ apart. All birds are marked out on field maps, especially individuals indicating a territory. Simultaneously singing individuals of the same species are noted as such, in order to detect neighbouring territories. Field maps are later converted to species maps, in which three registrations, or a nest, count as a permanent territory. In total 28 persons have carried out the surveys during the period 1972-2011.

\section{Processing of data}

Because other similar studies have dealt mostly with passerines (excluding corvids), so did we. Long-distance migrants have been considered one group, to be compared with residents, short- and medium-distance migrants combined. The reason for this grouping is that the two groups may be affected by partly different causes outside the breeding season.

Species turnover rate was calculated as the sum of new and disappearing species between two successive years, divided by the sum of the total number of species during both years (Svensson et al. 2010). Trends over time in the number of territories and species were analysed using Spearman rank correlation $\left(\mathrm{r}_{\mathrm{s}}\right.$ ). Analyses were made in GraphPad Prism (version 5.04 for Windows, GraphPad Software, La Jolla California USA, http://www. graphpad.com).

\section{Bird density}

On average 132 bird territories per year (all species) were registered in Ottenby lund, which result in a density of 1509 territories $/ \mathrm{km}^{2}$. When only passerines (except corvids) were considered, the density was 1474 territories $/ \mathrm{km}^{2}$ (Table 1). This is comparable to other Swedish broadleaved forests, such as Dalby Söderskog (Svensson 2009) and Sörön (recalculated from Johannesson 2005). However, the density in Fågelsångsdalen was $35 \%$ lower than in Ottenby lund (Enemar et al. 1994, Svensson et al. 2010). Interestingly, the well known primeval forest of Bialowieza National Park in Poland had a lower density. During the years 1995-1999 on average 1101 territories $/ \mathrm{km}^{2}$ were registered in the richest habitat dominated by ash/alder (Wesolowski et al. 2002, Tomialojc \& Wesolowski 2004). The total bird community in Sweden has recently 
been estimated to 70 million pairs, which means, on average, 170 territories $/ \mathrm{km}^{2}$ (Ottosson et al. 2012). Clearly, broadleaved forests in southern Sweden constitute a very rich bird habitat.

\section{Variation and trends in bird density}

The number of territories in Ottenby lund had a distinctive development during the 40 years (Figure 2, Table 2). During the first 20 years, the numbers increased, except for a dip during 1979-1987. Then, during the period of 1992-2011, the density gradually decreased and ended at almost the same level as in the beginning of the survey. This progress is largely inverted to the development of the number of birds at the national level (Ottvall et al. 2009). There was generally a significant decrease in Swedish bird numbers during 1975-1995, but thereafter the numbers have been mostly stable, or even increasing.

Several of the other long-term study localities showed trends that differ between each other as well as compared to national trends. For example, the number of territories in Fågelsångsdalen increased significantly during the period 1972-2009 (Svensson et al. 2010). This is a clear indication that local trends in bird numbers may not be correlated to large scale processes.

\section{Potential explanations to the variation in number of territories and species in Ottenby lund}

The large variation in number of territories in the survey plot of Ottenby lund is surprising in the light of the fact that rich habitats in a late stage of succession are generally supposed to be saturated (Fretwell \& Lucas 1970). We cannot see any changes in habitat that could explain the large variation, although it should be stated that no systematic documentation of habitat changes has been done.

Numerous Fallow Deer Dama dama and cattle have kept the understory vegetation low. However, the number of animals has varied quite a lot (von Schultz 1995). At present (2012), the winter population of Fallow Deer is estimated to 200 individuals (Johan Parboäng, pers. comm.). The number of cattle has fluctuated between 0 and 200 individuals (Andreas Wiström, pers. comm.).

Being part of Ottenby Nature Reserve, Ottenby lund has a specific management plan, including wood harvesting and clearing of "unwanted" vegetation. For example, 600 oaks were removed from the whole forest of Ottenby lund during the 1980's and 1990's. Around year 2000, many oaks were hit by "sudden oak death" (Håkan Lundkvist, pers. comm.). How this have affected the bird community is unknown.

The number of predators is also worth mentioning. Since the Red Fox Vulpes vulpes was almost extirpated by scabies during the 1990s, European Badger Meles meles and European Pine Marten Martes martes have become numerous in Ottenby lund (Johan Parboäng, pers. comm.). The badger is mostly a threat to species breeding on the ground, e.g. Willow Warbler Phylloscopus trochilus, whereas the marten may have a significant effect also on tree breeding species.

A large number of field workers (28) could possibly cause some variation. However, the largest change in number of territories between successive years was smaller than in Fågelsångsdalen and Ammarnäs, where much fewer field workers have been involved.

\section{Long- and short-distance migrants}

As a group, the long-distance migrants have faced less favourable circumstances compared to shortdistance migrants and residents, both in Sweden (Ottvall et al. 2009) and in the rest of Europe (Sanderson et al. 2006). Of the 37 passerine species breeding in Ottenby lund, 20 (54 \%) are longdistance migrants and 17 stay in Europe during the winter. The yearly proportion of long-distance migrant territories has on average been $42 \%$ (variation $32-53 \%$ ). There is no clear trend over the years $\left(r_{s}=-0.275, p=0.09\right)$, although the proportion increased slightly up to 1986 , after which there was a general decrease (Appendix 1). The number of both long- and short-distance migrant territories increased up to the middle of the 1990s, but in 2011 the numbers had gradually decreased down to similar levels as 40 years earlier (Table 2, Figure 2). There was a significant positive correlation between the two groups $\left(r_{s}=0.73, p<0.001\right.$, Figure 3 ), i.e. high numbers of long- and short-distance migrant territories occurred simultaneously, and vice versa. The number of long- and short-distance migrant species showed similar patterns as the number of territories (Table 2, Figure 4).

\section{Individual species}

The number of territories per species and year is presented in Appendix 1. Most bird communities in temperate regions are characterized by a few abundant species and many less common (Svensson 2006). This is also true for Ottenby lund. 
Chaffinch Fringilla coelebs and Willow Warbler together have made up on average $40 \%$ (24-52\%) of the number of territories. These two species also make up $31 \%$ of all birds in Sweden (Ottosson et al. 2012).

Except for Chaffinch and Willow Warbler, only four species have been represented all years in Ottenby lund: Tree Pipit Anthus trivialis, Icterine Warbler Hippolais icterina, Garden Warbler Sylvia borin and Spotted Flycatcher Muscicapa striata.

As for the whole bird community, the trends for the 13 most common species in Ottenby lund was often different from the national trends $(\mathrm{r}=0.203$, $\mathrm{p}=0.50$ ). Only three species in Ottenby lund showed a significant trend over the 40 years. All were increasing: Blackcap Sylvia atricapilla $\left(r_{s}=0.44, p=0.005\right)$, Garden Warbler $\left(r_{s}=0.42\right.$, $\mathrm{p}=0.008)$ and Common Starling Sturnus vulgaris $\left(\mathrm{r}_{\mathrm{s}}=0.40, \mathrm{p}=0.011\right)$. However, they all peaked around year 2000 and have since then occurred in lower numbers. 
Appendix 1. Antal revir av olika arter inom inventeringsrutan i Ottenby lund under perioden 1972-2011. Det finns inga data för 1998. Number of territories at Ottenby in 1972-2011. There are no data for 1998.

\begin{tabular}{|c|c|c|c|c|c|c|c|c|c|c|c|c|c|c|c|c|c|c|c|c|c|c|c|c|c|c|c|c|c|}
\hline & & & & & & & & & & & & & & & & & & & & & & & & & & & & Nedell & \\
\hline Art Species & 72737475 & & & 78 & 980 & 81 & 8283 & 3848 & 85 & 8687 & & 8990 & 909 & & 293 & & 95 & 969 & 9799 & & 01 & 020 & 0304 & 04050 & $\begin{array}{ll}06 & 07 \\
\end{array}$ & 08 & 091011 & 1 Mean & Artispecies \\
\hline Anas platyrhynchos & & & & & & & 11 & & 4 & \begin{tabular}{l|l}
31 \\
\end{tabular} & & & & 2 & & & 1 & 2 & & 1 & 1 & & 1 & & & & & 0.5 & Gräsand/Mallard \\
\hline Mergus merganser & & & & & & & & & & & & & & & & & & & & & & & 1 & & & & & 0.0 & StorskrakelGoosander \\
\hline Mergus serrator & & & & & & & & & & & & & 1 & & & & & & & & & & & & & & & 0.0 & SmåskrakelRed-breasted Merganser \\
\hline Gallinago gallinago & & & & & 1 & & & & & & & & & & & & & & & & & & 1 & & & & & 0.1 & Enkelbeckasini/Common Snipe \\
\hline Scolopax rusticola & & & 1 & & 1 & & & & & & & & & 1 & & & & & & & & & & & & & & 0.1 & MorkulalEurasian Woodcock \\
\hline Tringa ochropus & & & & & & & & & & 1 & & & & & & & & & & & & & & & & & & 0.0 & SkoogsnäppalGreen Sandpiper \\
\hline Columba oenas & & & & & 1 & & & & & & & & & & & & 2 & & & 11 & 11 & 2 & 2 & & & & & 0.3 & ShogsduvalStock Dove \\
\hline Columba palumbus & 111 & 3 & 1 & 31 & 1 & & 1 & 12 & 1 & 11 & & 11 & 1 & 11 & 2 & 22 & & 3 & 11 & 12 & 21 & 1 & 1 & & & & & 0.9 & RingduvalWood Pigeon \\
\hline Streptopelia turtur & 1 & & & & & & & & & & & & & & & & & & & & & & & & & & & 0.0 & Turturduva European Turtle-Dove \\
\hline Cuculus canorus & & & & 11 & 1 & & & 1 & 1 & 1 & & & & 1 & 2 & 21 & 1 & & & 1 & 1 & & 2 & & & & & 0.3 & GökCommon Cuckoo \\
\hline Strixi aluco & 1 & & & & 1 & 1 & 1 & 1 & & 1 & & & & & & 1 & & 1 & & & & & & & & & & 0.2 & KatugagalTauny OW' \\
\hline Picus viridis & & & & & & & & & & 1 & & & & & & 1 & & & 1 & & & & & & & & & 0.1 & GröngöinglGreen Woodpecker \\
\hline Dendrocopos major & & 1 & & & 1 & 1 & & 1 & 1 & 11 & & & 2 & 22 & 2 & 2 & 3 & 1 & 11 & & 21 & & 1 & 11 & 1 & & 1 & 0.8 & Större hackspettiGreat Spotted Woodpecker \\
\hline Anthus trivalis & $\begin{array}{llll}6 & 3 & 6 & 2\end{array}$ & 7 & 8 & 89 & 99 & 9 & 17 & 711 & 5 & 29 & 8 & $\begin{array}{ll}1217 \\
12\end{array}$ & 171 & 154 & 46 & & 12 & 6 & 45 & 57 & \begin{tabular}{l|l}
7 & 7 \\
\end{tabular} & 6 & 8 & 54 & \begin{tabular}{l|l}
4 & 4
\end{tabular} & 42 & $\begin{array}{lll}4 & 6 & 2\end{array}$ & \begin{tabular}{|l|l|}
2 & 6.6 \\
\end{tabular} & Trädpipläkal Tree Pipit \\
\hline Motacilla alba & & 1 & 2 & 23 & 31 & 13 & & 1 & 1 & 11 & 1 & 21 & 1 & & 2 & 4 & 4 & & 1 & & 11 & 2 & 1 & & & & & 1.0 & SädesàralaWhite Wagtail \\
\hline Prunella modularis & & & & & & & & & & & & & & & & & & & & & & & & & 1 & & & 0.0 & JämsparvilHedge Accentor (Dunnock) \\
\hline Troglodyes troglodyes & 1 & & & & & & 1 & 1 & & 1 & 4 & 23 & 3 & 23 & 36 & $\begin{array}{ll}6 & 3 \\
\end{array}$ & 7 & 2 & 35 & 55 & $5 \quad 5$ & 5 & 7 & 53 & \begin{tabular}{l|l}
3 & 9 \\
\end{tabular} & 94 & $\begin{array}{llll}4 & 1 & 2\end{array}$ & 2.5 & GärdsmyglWinter Wren \\
\hline Erithacus rubecula & 22 & 1 & & & & & & 1 & & & & 43 & 3 & 41 & 1 & & 1 & & & & 11 & & & & & 11 & 21 & 0.7 & RoodhakelEuropoean Robin \\
\hline Luscinia luscinia & 1 & & & & & & & & & & & 12 & 2 & 31 & 11 & & & & & & 21 & & & & & & & 0.3 & Näkergall Thrush Nightingale \\
\hline Phoenicurrus phoenicurus & & & & & & & & & & & & 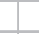 & 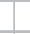 & & & & & & & & & 1 & & 3 & & & & 0.1 & RödstiärtCommon Redstart \\
\hline Turous merula & $\begin{array}{lllll}3 & 5 & 5 & 3\end{array}$ & 3 & 3 & $\begin{array}{ll}5 & 3\end{array}$ & $\begin{array}{ll}3 & 3 \\
\end{array}$ & 3 & 1 & 13 & 4 & 21 & 5 & 44 & 4 & 43 & 33 & 38 & 1 & 5 & \begin{tabular}{l|l}
45 \\
4
\end{tabular} & 57 & \begin{tabular}{l|l|}
7 & 4
\end{tabular} & 4 & 35 & 5 & \begin{tabular}{l|l|}
3 & 1
\end{tabular} & 11 & $\begin{array}{llll}4 & 2 & 1\end{array}$ & 3.3 & Koltrast Eurasian Blackbird \\
\hline Turdus pilaris & 12 & 1 & & & & & 1 & 1 & & & & 23 & 3 & 22 & 2 & 6 & 8 & 1 & & $\begin{array}{ll}62 \\
\end{array}$ & 22 & 5 & 42 & 2 & & & & 1.3 & Bö̈riktrastifFieldfare \\
\hline Turdus philomelos & 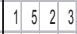 & 4 & 3 & 23 & 32 & 21 & 1 & 1 & 1 & 1 & & 11 & 1 & 24 & 4 & 1 & 3 & 2 & & 11 & 12 & 1 & 2 & & 1 & & & 1.3 & TaltrastSSong Thrush \\
\hline Hippolais icterina & \begin{tabular}{|l|l|l|l|}
12 & 1 & 1213 \\
\end{tabular} & 13 & 13 & 1415 & $15 \quad 14$ & 413 & \begin{tabular}{|l|l|}
12 & 1 \\
\end{tabular} & 113 & 9 & 115 & 9 & $\begin{array}{ll}1313 \\
\end{array}$ & 13 & 17 & 79 & 911 & 12 & 13 & 11 & 17 & 71 & 71 & 121 & 1191 & 1115 & 59 & 996 & \begin{tabular}{l|l|l|}
6 & 9.4 \\
\end{tabular} & Halmsángarellcterine Warbler \\
\hline Acrocephalus palustis & & & & & & & & & & & & & & & & & & & & & & & & & & & & 0.0 & KärrsàngarelMarsh Warbler \\
\hline Sylvia communis & & & & & & & & & & & & & & & 1 & & & & & 1 & 1 & & & & & & & 0.1 & TörsàngarelCommon Whitethroat \\
\hline Sylvia borin & 45553 & 3 & 4 & 45 & 55 & $5 \quad 5$ & 67 & 77 & 4 & 92 & 3 & 68 & 8 & $\begin{array}{ll}6 & 6 \\
\end{array}$ & 66 & $\begin{array}{ll}6 & 8 \\
\end{array}$ & 15 & 8 & 1617 & & 615 & 1 & 78 & 86 & $\begin{array}{ll}9 & 7 \\
\end{array}$ & 73 & 3610 & \begin{tabular}{l|l|l|}
0 & 6.9 \\
\end{tabular} & Trädgardss sangarelGarde \\
\hline Sylvia atricapilla & 321 & 3 & 3 & 23 & 31 & 1 & 31 & 11 & & $\begin{array}{ll}13 \\
\end{array}$ & 4 & 75 & 5 & 87 & 77 & 73 & 5 & 4 & 44 & 47 & 72 & 4 & 5 & 21 & $\begin{array}{ll}2 & 4 \\
\end{array}$ & 43 & 298 & \begin{tabular}{|l|l|}
8 & 3.4 \\
\end{tabular} & SvarthätlaBlackcap \\
\hline Phylloscopus trochiliodes & & & & & & & & & & & & & & 1 & 1 & & & & & & & & & 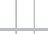 & & & & 0.0 & LundsảngarelG Greenish Warbler \\
\hline Phylloscopus sibilatixix & $\begin{array}{lllll}4 & 3 & 2 & 1 \\
\end{array}$ & 2 & 6 & 48 & 81 & 13 & $\begin{array}{ll}1 & 1 \\
\end{array}$ & 13 & 1 & 2 & 6 & 67 & 7 & 88 & 81 & 17 & 5 & 3 & 2 & 54 & $4 \quad 4$ & 3 & 12 & 21 & 10 & 03 & $\begin{array}{llll}4 & 3 & 2\end{array}$ & 23.5 & GrönsảngarelWood Warbler \\
\hline Phylloscopus collybita & & 1 & & & 1 & & & & 1 & 1 & 2 & 21 & 1 & 1 & 12 & 21 & 3 & 1 & 2 & 1 & 1 & & & 1 & & & & 1.4 & GansangngarelChiftchaff \\
\hline Phylloscopus trochilus & 9845 & 5 & 7 & 1110 & 1010 & 14 & 1617 & 717 & 15 & 2117 & 16 & 1918 & 181 & 1615 & 1518 & $\begin{array}{ll}8 & 12 \\
\end{array}$ & 15 & 12 & 1728 & 2826 & $\begin{array}{ll}621 \\
\end{array}$ & 153 & 3135 & 3591 & \begin{tabular}{l|l|}
10 & 13 \\
\end{tabular} & 310 & $\begin{array}{llll}11 & 13 & 7 \\
\end{array}$ & 15 & LövsángarelWillow Warbler \\
\hline Muscicapa striata & $\begin{array}{lllll}1 & 3 & 7 & 4 \\
\end{array}$ & 6 & 5 & 511 & 1118 & B 1 & 88 & 86 & 5 & 112 & 7 & 18 & 8 & 94 & $\begin{array}{ll}4 & 6 \\
\end{array}$ & 6 | 15 & 14 & 5 & 7 & 87 & $7 \quad 9$ & 4 & 9 & 15 & \begin{tabular}{l|l}
6 & 3 \\
\end{tabular} & 35 & $\begin{array}{llll}3 & 1 & 2\end{array}$ & \begin{tabular}{l|l|l|}
2 & 5.9 \\
\end{tabular} & Grá flugsnapparelSpotted Flycatcher \\
\hline Ficedula parva & 1 & & & 21 & 1 & & 1 & 1 & 1 & 31 & & 1 & & & 11 & 11 & & & & & 1 & & & & & & & 0.4 & Mndref flugsnappare Red-breasted Flycatcher \\
\hline Ficedula albicollis & & & 1 & & 1 & & 1 & & & 1 & & 11 & 1 & 1 & & 2 & & & & 1 & & 1 & & 1 & & & & 0.3 & HasbandsflugsnapparelCollared Flycatcher \\
\hline Ficedula hypoleuca & 1332 & & 1 & 21 & 13 & $\begin{array}{ll}3 \\
\end{array}$ & 21 & 11 & 1 & & 1 & 33 & 3 & 12 & 22 & 22 & 2 & 2 & & & 1 & & & & & 1 & 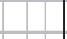 & 1.0 & Svartitif flugsnappare/Pied Flycatcher \\
\hline Ficedula hypolecuca $+F$. alb & bicollis (intersp & vecific $p$ & & & & 1 & & & & & & & & & & & & & & & & & & & & & & 0.0 & Svartyit flug. + Halsbandsfiug./Pied + Collared Flycatcher \\
\hline Ficedula hypolecuca X F. alt & bicollis (male hy & & & & & & 1 & & & & & & & & & & 1 & & & 1 & 1 & & & & & & & 0.1 & Hybrifflugsnappare (hannen)/Pied X Collared Flycatcher \\
\hline Aegithalos caudatus & & & & & & & & & & & & & & 11 & 1 & & & 1 & & & & & & 11 & & & & 0.1 & StäartmesLlong-taleded Tit \\
\hline Cyanistes caeruleus & \begin{tabular}{|l|l|l|}
8 & 1 & 5 \\
\end{tabular} & 7 & 4 & 54 & 44 & 44 & 2 & 26 & 6 & 6 & 7 & 514 & 141 & 138 & 84 & $4 \quad 1$ & 14 & 9 & 6 & 64 & $4 \quad 5$ & 4 & 48 & 85 & \begin{tabular}{l|l|l|}
4 & 4 \\
\end{tabular} & 411 & 994 & \begin{tabular}{l|l|l|}
4 & 5.5 \\
\end{tabular} & BlamessBlue Tit \\
\hline Parus major & $\begin{array}{lllll}6 & 2 & 3 & 1\end{array}$ & 3 & 3 & 53 & $\begin{array}{ll}3 & 4\end{array}$ & 4 & 12 & 29 & 4 & 43 & 7 & 37 & 7 & 77 & 75 & $5 \quad 5$ & 8 & 3 & 4 & 66 & $\begin{array}{ll}6 & 5\end{array}$ & 3 & 4 & 92 & \begin{tabular}{l|l}
4 & 3
\end{tabular} & 33 & $\begin{array}{llll}4 & 3 & 2\end{array}$ & \begin{tabular}{|l|l|}
2 & 4.2 \\
\end{tabular} & TalgoxelGreat Tit \\
\hline Sitta europea & & & & 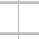 & & & & & & & & & 1 & 1 & 12 & 22 & 2 & 1 & 2 & 11 & 11 & 2 & 12 & 21 & \begin{tabular}{l|l|}
1 & 1 \\
\end{tabular} & 11 & 1 & 0.6 & NöväckalWood Nuthatch \\
\hline Certhia familiaris & $\begin{array}{llll}1 & 2 & 2 & 1 \\
\end{array}$ & 1 & 3 & $\begin{array}{ll}33 \\
\end{array}$ & 33 & 32 & 11 & 11 & 1 & 21 & 1 & 23 & 3 & 23 & 36 & $6 \quad 3$ & 3 & 2 & 2 & $\begin{array}{ll}45 \\
4\end{array}$ & $5 \quad 5$ & 2 & 3 & 41 & 1 & 2 & 1 & 2.1 & TräakyparelEurasian Trecreceper \\
\hline Oriolus oriolus & 1 & 1 & 1 & 11 & 11 & 1 & & & & & 1 & & & & 2 & 23 & 2 & & 1 & 11 & 11 & & & & & & & 0.5 & SormargyllinglEurasian Golden Oriole \\
\hline Lanius collurio & & & & & & 1 & & & & & & & & & & 1 & & & & & 1 & 2 & 1 & & & & & 0.2 & TornskatalRed-backed Shrike \\
\hline Corvus corone cornix & & & & & & & & 1 & 1 & 1 & & 1 & & & 11 & & 1 & 2 & 1 & & 11 & & & & & & & 0.3 & Kákal/Hooded Crow \\
\hline Stumus wigaris & $\begin{array}{lll}13 & 2 & 7 \\
\end{array}$ & 6 & 1 & 1813 & 1311 & 11 & 1313 & 318 & 18 & 1912 & 11 & 1411 & 111 & 191 & 117 & $7 \quad 23$ & 41 & 24 & 214 & & 318 & 12 & & 17172 & $\begin{array}{ll}25 & 27 \\
\end{array}$ & 716 & $\begin{array}{llll}13 & 13 & 9\end{array}$ & \begin{tabular}{l|l|l}
9 & 14.8 \\
\end{tabular} & StarelCommon Starling \\
\hline Fringilla coelebs & 21213431 & 41 & 46 & & & 47 & 4031 & 128 & 25 & 2226 & 394 & 4240 & 40.4 & 4138 & 3843 & 338 & 38 & 35 & 433 & & 535 & 254 & & 4827 & \begin{tabular}{|l|l|}
42 & 41 \\
\end{tabular} & & 332827 & \begin{tabular}{l|l|l|}
77 & 35.8 \\
\end{tabular} & BofinkChaffinch \\
\hline Carduelis chloris & & & & & & & & & & & & & & & & & & & 1 & 1 & 1 & 1 & & & & & & 0.1 & GönfinkEEuropean Greenfinch \\
\hline Carduelis carduelis & & & & & & & & & & & & & & & 1 & 1 & & & & & & 1 & & & & & & 0.1 & Steglits/European Goldfinch \\
\hline Carpodacus engthrinus & 1 & & & & & & & & & 1 & & & & & & & & & & & & & & & & & & 0.1 & Rosenfink Common Rosefinch \\
\hline Coccothraustes coccothrau & & & & & & 1 & & 1 & 1 & 1 & & & & & & 2 & & & 1 & 3 & 21 & 1 & & & & & & 0.4 & StenknäckKHawinch \\
\hline Emberiza citrinella & & & & & & & & 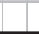 & & 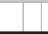 & 1 & 12 & 2 & 11 & 1 & 2 & 6 & 4 & 2 & 57 & $\begin{array}{ll}7 & 6 \\
\end{array}$ & 5 & 3 & 43 & \begin{tabular}{l|l|}
6 & 4 \\
\end{tabular} & 43 & \begin{tabular}{|l|l|}
2 & 2 \\
\end{tabular} & \begin{tabular}{|l|l|}
2 & 1.8 \\
\end{tabular} & GusparviYyellowhammer \\
\hline \begin{tabular}{|l|} 
Antal revirl \\
Number of territories \\
\end{tabular} & 77809 & & & & & & 10999 & & & & & & & & & & & & & & & & & & & & & 133 & Antal re \\
\hline \begin{tabular}{|l|} 
Antal arterl \\
Number of species
\end{tabular} & & & & & 23 & 18 & 1720 & 24 & & 2420 & 192 & 2627 & & & & 3 3 33 & 29 & & & & & 282 & & & & & 171416 & 22 & 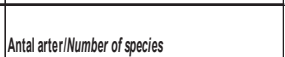 \\
\hline \begin{tabular}{|l|} 
Antal arter kumulativit \\
Cumulative number of \\
species
\end{tabular} & 1 & & & & -1 & & & & & - & 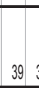 & 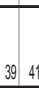 & & & & & & & & & & & & $4949 / 3$ & 5050 & & 0 & & ivtl rof species \\
\hline
\end{tabular}

